\title{
Instructional Serendipity amid Diversity
}

\author{
Asa B. Wilson', Kyle J. Casler ${ }^{2}$ \\ ${ }^{1}$ Department of Management, Southeast Missouri State University, Cape Girardeau, MO, USA \\ ${ }^{2}$ Methodist University, Fayetteville, NC, USA \\ Email: abwilson@semo.edu
}

How to cite this paper: Wilson, A. B., \& Casler, K. J. (2021). Instructional Serendipity amid Diversity. Open Journal of Social Sciences, 9, 388-396. https://doi.org/10.4236/jss.2021.91029

Received: November 25, 2020

Accepted: January 25, 2021

Published: January 28, 2021

Copyright $\odot 2021$ by author(s) and Scientific Research Publishing Inc. This work is licensed under the Creative Commons Attribution International License (CC BY 4.0).

http://creativecommons.org/licenses/by/4.0/ (c) (i) Open Access

\begin{abstract}
Colleges and universities are faced with mission and instructional challenges. Society is emphasizing respect for diversity and inclusion. Higher education is working to ensure that individual and student group differences do not hinder academic progress or frustrate retention. Unfortunately, diversity can atomize a campus environment making instructional engagement difficult. A case-study approach to an in-class response describes an engaging experience that arose unexpectedly from a diverse class. This event is discussed as a serendipitous epiphenomenon anchored in class diversity yet transcending these differences. It is also a paradox since it cannot be instructionally scripted and will be overlooked if it is not considered a possibility. Equally unexpected gains in class climate and course content are discussed. Methods for fostering the probability of instructional serendipity are identified.
\end{abstract}

\section{Keywords}

Diversity, Student Engagement, Academic Community

\section{Introduction}

A concern for diversity, equality, and opportunity has a history dating from the Civil War to the 1964 Civil Rights Act and beyond. This emphasis and its protection against discrimination based on differences continue as a political and cultural feature of the US society. This leveling of the playing field has become a priority in higher education, a dynamic unfolding under the umbrella of diversity, inclusion, and retention (Harris \& Lee, 2019; Clauson \& McKnight, 2018; Misra \& McMahon, 2006). It is driven by a sensitivity to differences by ensuring that no one is left behind, i.e., discriminated against. Embracing diversity and inclusion involves minimizing factors that frustrate individuals and student groups from achieving their educational goals. A subsequent concern for colleges and university is the extent to which diversity and inclusion policies tend to create 
student factions and thereby foster division, especially in a classroom's interpersonal climate.

\subsection{Purpose}

The purpose of this paper is to use a case-study to define a positive in-class event that highlights an unexpected (serendipitous) instructional gain emerging from diversity. This emergence is a class-wide-benefit that can be overlooked or missed when diversity is treated in statutory, diagnostic, or character terms. Also, the paradoxical feature of instructional serendipity is that since it cannot be made to happen, it will be overlooked or missed by not expecting that it could happen.

\subsection{Diversity in Higher Education}

Diversity sensitivity has expanded to include physical disabilities, first-generation status, academic readiness, work demands, family challenges, medical conditions, and learning disabilities. For example, "Accommodations might include extended time on tests, audio recordings or readings, assistance with note taking, recorded lectures, or having tests read aloud in a separate setting" (Chandler, Zaloudek, \& Carlson, 2017). Also, diversity acknowledges neuroscience realities associated with learning, e.g., "Although incredibly complex and interrelated, neuroscience reveals that there are three basic components to learning which includes how we recognize information, the strategies employed to process that information, and the paths to engage with learning" (Goswami, 2013; Rose \& Strangman, 2007).

The breadth of diversity recognized by the academy is simultaneously creating instructional challenges and opportunities. Chandler, Zaloudek, \& Carlson (2017) pose that academia has "an ethical obligation rooted in the ideal of equal opportunity, to address the needs of academically diverse students" (p. 152). An overarching task is to balance respect for diversity while maximizing opportunities for engagement.

\section{Case Study-An Epiphenomenon from Diversity}

Instructional serendipity is defined as an epiphenomenon class experience or dynamic that emerges unexpectedly with positive class content and engagement results. From a diverse classroom, an epiphenomenon arises and transcends differences. In doing so, this experience also enhances content appreciation and mastery. Ignatieff (2017) has shown how, in extremely diverse situations, diversity is transcended creating a sense of community in which interpersonal virtues emerge. This transcendence is an epiphenomenon because it is not seen amid obvious diversity, yet it arises from diversity when least expected.

The case-study posits that each student is more than race, religion, gender, national origin, or other diversity marker. Thus, each student brings a unique set of life experiences. These attributes also are linked to 1) how they approach learning and 2) what captures their interest. When these demographic class features are overlooked, unexpected instructional and engagement opportunities 
may be lost. The specific serendipitous instructional example is portrayed as follows:

\subsection{Location}

The academic setting is a small, private, faith-based university with a school of health sciences. The university is uniquely situated in a community of 400,000 that is home to a large Army installation. University day and evening classes have several Army veteran, retiree, dependents, or active duty personnel enrolled. Students with an Army affiliation have established themselves as a diversity factor in the university's student demographics. In addition, this group stands out because of the individual and collective maturity of its members, attributes expressed in in-class conduct and academic performance.

\subsection{Course and Assignment-Escape Fire Video}

The course, Introduction to Healthcare Administration, is a foundation for subsequent courses in the health administration major. Course objectives are to equip students to 1) be conversant with the key elements of the US health industry, 2) know the interplay among these components, and 3) understand healthcare management challenges. Since few students have employment experience in health services, the course introduces the dynamic unfolding within each system element and throughout the industry. This focus enables students to understand current trends and envision future developments.

The Escape Fire documentary (Heineman \& Froemke, 2012) is used as an instructional support. To begin, the video defines the escape-fire concept which is a problem-solving metaphor and template derived from an actual emergent forest-fire fighting situation. The escape-fire model challenges the existing complexity of today's health service approaches and costs. Once understood, students are asked to identify escape-fire applications portrayed in the video's eight healthcare topic threads.

Military medicine is one thread devoted to the issue of pain management and the risk of opioid misuse for returning wounded soldiers. Once the problem is introduced, this thread follows a soldier returning from Afghanistan. SGT Robert Yates is seen from medivac transport out of theater through rehabilitation at Walter Reed Hospital (WRAH) to discharge home. The narrative highlights the challenges created by the volume of wounded returning troops. It also demonstrates alternative pain-management and therapeutic approaches available to facilitate a wholistic rehabilitation.

\subsection{The Class and Instructional Serendipity}

This class was quite diverse and representative of the university's demographic mix. Also, several students had military links, e.g., active duty, separated from active duty, retired, and dependents. The group also represented a range of ages, marital status, international origins, work demands, family ties, and child-rearing 
responsibilities.

As a Fall course, everyone came dressed for cold weather. Half-way through, the temperature crept into the low-70 s making summer attire the "uniform of the day". I noticed a student walking with the aid of a below-the-knee prosthesis. Given my rehabilitation background, I was impressed with the quality of his gate. Since I had a good relationship this student, it was acceptable to ask, "How did you accomplish such a perfect gate?"

In this after-class discussion, SPC Casler told me he stepped on an Improvised Explosive Device (IED) while on patrol in Afghanistan. He said, "I spent a rehabilitation year at WRAH and that's where I worked on my gate". Interestingly, he was in WRAH in 2012 during the filming of Escape Fire. SPC Casler shared an interest in comparing his rehab experiences with those reported in the video. I asked Kyle to share his military medicine experiences with the class once we finished the video.

\section{SPC Casler's Voice and Perspective}

This section focuses on my 1) reason for being in the class, 2) purpose for pursuing a degree, and 3) rationale for choosing a major. My introduction to academia, reasons for choosing certain courses over others, and pursuing a Kinesiology major are woven together by a myriad of life events. With the support of my family and the financial safety net provided by the Post 9/11 GI bill, I was able to embark on any academic path possible. I settled on Kinesiology based on the intimate relationship I had as a physical therapy patient after a below-theknee amputation.

From an education standpoint, a degree in Kinesiology was the best way I could see to participate in the profession. It was not until my last university semester that I chose to enroll in Dr. Wilson's class. I chose the course is because it was not required for my degree plus I needed only one elective to graduate.

It was a conscious decision to take the course based on the administrative aspects of the healthcare system I presumed to gain. At this time, I was unaware of the learning opportunities the course would afford me. To name a few, they include a) sharing my unique story amongst a group of peers, b) establishing personal connections that immediately followed, and c) seeing the professional post-graduate doors that could open.

\subsection{Response to Escape Fire Assignment-SPC Casler}

A satisfying feeling as a student is the ability to make a connection between an assignment and my personal life. This is also the area in academia that has the greatest potential for learning. There was a class assignment that achieved this very notion-Escape Fire: The Fight to Rescue American Health Care. From my student's perspective, the video delivers an overview of how the US. Healthcare system works and points out its shortcomings. For example, the over-prescription of opioids, the opioid crisis, was used as one of military medicine's shortcomings. 
Escape Fire delivers a model for problem solving by utilizing readily available resources and unconventional creative thinking to achieve success in an emergent situation. Also, military medicine serves as a microcosm of what is happening nationally. In this scenario, a soldier, like me, hospitalized at WRAH for injuries sustained as an infantryman while deployed in Afghanistan is followed. SGT Robert Yates was treated with conventional method of prescription drugs. The Escape Fire model for success is found in SGT Yates' journey for a better and drug-free solution.

There is a vivid scene evoking intense emotional attention where SGT Yates rips open a grocery bag full of prescription drugs and pours out all the bottles that eventually land at his feet as he sits in his wheelchair with his head in his hands. Following this, the opportunity for military medicine's creative thinking skills and alternative therapies are shown. Eventually through guided meditation, group therapy, acupuncture, and a supportive military and civilian staff at WRAH, SGT Yates fully recovers and makes his way home. He happily credits those individuals and alternative therapies for his recovery and positive future.

\subsection{Personal Reflection-SPC Casler}

I did not cross paths with SGT Yates in 2012. Yet, throughout the video, I kept reflecting on my experiences and the parallels between my treatment and SGT Yates' care. My placement at WRHA was due to wounds sustained from stepping on an IED during a combat patrol in 2012. Even though the IED only partially detonated, the wounds were severe enough that a below-the-knee amputation was required. Without it, the compounding issues created a significant health risk.

As with SGT Yates, part of my post-amputation recovery involved narcotic painkillers for pain management. It was, and still is, considered a normal approach for treating pain in military medicine. The major drawback is the addiction that rides the drugs' coat tails. I cannot recall every drug prescribed, but I remember attempting to count the pills in my medicine cup. I came up with a count of fifteen not including two IV poles holding various bags. At the time, I did not know if that number was high or low. However, by reflecting on my treatment and SGT Yates', it was easy to see how we both became addicted to prescription narcotics during rehabilitation.

The parallels between our experiences also continued throughout the recovery phase. Post-addiction, SGT Yates was offered alternative options for pain management. Most aligned with the escape-fire model was the use of acupuncture and guided imagery. SGT Yates admits to being skeptical at first but was willing to try anything. They worked for him. Although my therapy varied regarding pain management, our paths were similar in treating our mental health difficulties.

I credit group therapy sessions for helping me find the correct coping mechanisms for post-traumatic stress disorder (PTSD). SGT Yates credits his guided meditation sessions for the same result. The betterment of our mental health had 
more influence on our overall recovery compared to overcoming addiction. However, I also believe we would not have been able to thrive in our respective therapy sessions if we were still addicted to prescription drugs. For these reasons, I have a new profound appreciation for military medicine and its ability to bend and adapt to situations with at-hand resources-a current-escape fire example.

My unexpected likeness to SGT Yates' experience shown in Escape Fire is perhaps the reason Dr. Wilson-after getting to know me and talking with me before and after classes-approached me to share in-class my story as a link for the Escape Fire theme. I believe this opportunity provided a unique perspective and opportunity for everyone in the class. From an educational standpoint I was able to provide the class with my personal experience in combination with lecture material to confirm the escape-fire theme in a real-world setting.

\section{Discussion}

SPC Casler's personal presentation and the serendipitous class response fostered an unexpected, positive, and lasting instructional outcome. An often-overlooked feature of diversity is the covert commonalities or core commonality present in a group. This invisible reality, when piqued, can draw a group together in positive, unexpected ways. Chandler, Zaloucek, and Carlson (2017) have identified ways to foster such an instructional windfall within a diverse classroom. Instead of being surprised by unexpected surfacing of commonalities, they identify ways to "maximize success in the academically diverse classroom". These are structured approaches that sensitize one to the community value of diversity.

\subsection{Case-Study Review}

A key lesson is that Mr. Casler's presentation had an unexpected impact on the class. For the remainder of the semester, class attendance improved, subsequent group presentations were more engaging, and pre-class discussions were more personable and supportive. Also, a critical class attitude toward less-performing students morphed into a supportive, encouraging climate. In Ignatieffs (2017) terms, the class acquired attributes of a community in answer to the question, "Beneath all our differences, what virtues, principles, and rules of conduct are we coming to share?" (p. 4).

First, several students had experience with military medicine while on active duty or via the VA health system following discharge. This commonality emerged during the spontaneous post-presentation Q\&A discussion. Second, students with no military links were equally engaged. They were captured by the important role military medicine plays for active-duty personnel, especially returning wounded soldiers. Both groups were united in their interest in military medicine, especially the pain-management and rehabilitation challenges. Third, this experience clarified the class's understanding of the civilian opioid crisis and the value of alternative therapies. A valuable insight emerged that opioid abuse is not an ex- 
clusive consequence of managing physical pain.

It is important that the case-study event is not viewed as limited to one course, specific course content, or instructional setting. Rather, a serendipitous epiphenomenon is a potential emergent in any higher education instructional location. Course content and structure create an instructional framework with a defined task, clear expectations, and set boundaries. Thus, each class has the potential to transcend diversity and stimulate a sense of community that enhances learning.

\subsection{Fostering Opportunities for Serendipity}

These outcomes could not have been scripted or built into the syllabus. However, opportunities exist to prepare for the possibility of a serendipitous event. One such approach is to capitalize on the obvious instructional value of classroom diversity.

For example, Asian students eagerly explain how their health system integrates eastern and western therapies. Saudi students clarify how the Ministry of Health is expanding rural health services. Students from less-developed countries are excellent representatives of their national healthcare system's challenges. United Kingdom students are skilled narrators of the strengths and limitations of their National Health System. The willingness of international students to discuss their country's health system is a positive instructional resource. Such presentations strengthen international students' sense of belonging and expands other students' understanding of international health systems. These portrayals also foster lively discussions about the potential application of international approaches to U.S. healthcare reform (Fanning, Aronson-Rath, \& Reid, 2008; Reid, 2010).

Another structured approach is using an Affinity Chart as an in-class brainstorming exercise. Building an Affinity Chart encourages everyone to express ideas about the identified issue-an engagement opportunity that identifies commonalities within the group.

Further, before his in-class presentation, SPC Casler distinguished himself as a respected, non-traditional student colleague. He arrived early for class, read a history book, or visited with his class colleagues. He also participated in a respectful give-and-take dialogue with the instructor. His participation was an engagement foundation that enabled his in-class presentation to have a compelling, unexpected impact.

\subsection{Expanded Relevance of Instructional Serendipity}

The emergence of instructional serendipity is dependent upon a prior foundation of engagement with students. As such, the case-study event underscores a diversity-related challenge confronting colleges and universities. That is, areas of the country are experiencing declines in social capital, economic and social mobility, especially among its youth (Carney, 2019; Putnam, 2013, 2015; Vance, 2018). Economic mobility is one's ability to exceed parental social and economic status via successful competition in today's world of work. This distress is dis- 
cussed as diminished social capital as barrier to realizing the American dream. Further, a college degree is now a vital attainment because it leverages economic mobility and career progress.

This means that students come to class with a shared purpose. They assess course content and instructor engagement from a long-term perspective, e.g. "How will this stuff help me reach my goals?" To this end, instructional serendipity, when it occurs, fosters a sense of classroom community that facilitates seeing beyond the degree and encourages informed preparation.

Within class boundaries and expectations, the campus-as-a-whole becomes a community, a bulwark to personal development and career readiness. Unfortunately, the COVID-9 outbreak disrupted the campus-as-community resource upon which students rely for a sense of identity and belonging. Student frustration and anger over being a) evicted from campus housing and b) forced into a virtual instructional environment are testimony to the campus-as-community's importance. Even synchronous Zoom sessions were not accepted as community substitutes for F2F classes. If they were equivalents, there would not have been litigation against paying full-tuition costs for on-line courses.

Finally, a lesson learned emerged as a challenge-opportunity for the academy. Student reactions to the academy's COVID-19 strategy confirm the challenge. Nisbet's (1953) classic, The Quest for Community, posits that the need for community is a compelling human motive because we are by nature social "animals". The desire for positive affiliation is satisfied initially in kinship groups, e.g., the family, religious association, and the local community. Nisbet shows how these elements of community are "essentially prior to the individual and are the indispensable supports of belief and conduct. Release man from the contexts of community and you get not freedom and rights but intolerable aloneness and subjection to ... fears and passions" (p. 25).

As elements of the primary community weakened, so did opportunities for the social and economic mobility of subsequent generations (McCloskey \& Mathur, 2020; Carney, 2019; Putnam, 2015; Putnam, 2013: Murray, 2013; Vance, 2018). By default, colleges and universities "adopted" these individual because these institutions support overcoming a sense of alienation and barriers to social mobility.

The serendipitous experience foreshadows the opportunity. The academy's COVID-19 response revealed that students have, in turn, "adopted" their university as a vital transition-support community. Also, the in-class epiphenomenon emerges from the campuses reverence for diversity as an expression of the underlying quest for community existing among students, albeit not always overt.

Thus, colleges and universities now face the challenge of working with students arriving with heightened expectations about the importance of the campus community. This challenge elevates student success via engagement to a priority second only to recruitment. At the instructional level, the opportunity becomes one of fostering student success without compromising learning-an ideal time to prepare for and anticipate serendipitous instructional events (Neem, 2019). 


\section{Conflicts of Interest}

The authors declare no conflicts of interest regarding the publication of this paper.

\section{References}

Carney, T. P. (2019). Alienated America: Why Some Places Thrive While Other Collapse. New York: HarperCollins Publishers.

Chandler, R., Zaloudek, J. A., \& Carlson, K. (2017). How Do You Intentionally Design to Maximize Success in the Academically Diverse Classroom? New Directions for Teaching and Learning, No. 151, 151-169. https://doi.org/10.1002/tl.20254

Clauson, C., \& McKnight, J. (2018). Planning for Diversity, Inclusion, and Equity. Planning for Higher Education Journal, 47, 39-48.

Fanning, A.-R., \& Reid, T. R. (2008). Sick around the World. Boston, MA: WGBH Educational Foundation.

Goswami, U. (2013). Neuroscience and Education: From Research to Practice? Nature Reviews Neuroscience, 7, 406-418. https://doi.org/10.1038/nrn1907

Harris, T. M., \& Lee, C. N. (2019). Advocate-Mentoring: A Communicative Response to Diversity in Higher Education. Communication Education, 68, 103-131. https://doi.org/10.1080/03634523.2018.1536272

Heineman, M., \& Froemke, S. (2012). Escape Fire. The Fight to Rescue American Healthcare. New York: Our Time Projects.

Ignatieff, M. (2017). The Ordinary Virtues: Moral Order in a Divided World. Cambridge, MA: Harvard University Press. https://doi.org/10.4159/9780674981683

McCloskey, A. M., \& Mathur, A. (2020). The Power of Community. National Affairs, 44, 132-144.

Misra, S., \& McMahon, G. (2006). Diversity in Higher Education: The Three Rs. Journal of Education for Business, 82, 40-43. https://doi.org/10.3200/JOEB.82.1.40-43

Murray, C. (2013). Coming Apart: The State of White America, 1960-2010. New York: The Crown Publishing Group.

Neem, J. N. (2019). What's the Point of College? Seeking Purpose in an Age of Reform. Baltimore, MD: Johns Hopkins University Press.

Nisbet, R. A. (1953). The Quest for Community: A Study in the Ethics of Order and Freedom. New York: Oxford University Press.

Putnam, R. D. (2013). Bowling Alone: The Collapse and Revival of American Community. New York: Simon \& Schuster.

Putnam, R. D. (2015). Our Kids: The American Dream in Crisis. New York: Simon \& Schuster.

Reid, T. R. (2010). The Healing of America: A Global Quest for Better, Cheaper, and Fairer Health Care. New York: Penguin Publishing Group.

Rose, D. H., \& Strangman, N. (2007). Universal Design for Learning: Meeting the Challenge of Individual Learning Differences through a Neurocognitive Perspective. Universal Access in the Information Society, 5, 381-391. https://doi.org/10.1007/s10209-006-0062-8

Vance, J. D. (2018). Hillbilly Elegy: A Memoir of a Family and Culture in Crisis. New York: HarperCollins Publisher. 